\title{
Understanding the Role of Complexation of Fluoroquinolone and $\beta$-Lactam Antibiotics with Iron (III) on the Photodegradation under Solar Light and UVC Light
}

\author{
Efraím A. Serna-Galvis ${ }^{1,2, *}$, Yudy L. Martínez-Mena ${ }^{2}$, Jazmín Porras ${ }^{1}$, Yenny Ávila-Torres ${ }^{2} \mathbb{O}$, \\ Javier Silva-Agredo ${ }^{2}\left(\mathbb{D}\right.$ and Ricardo A. Torres-Palma ${ }^{2, *(D)}$ \\ 1 Grupo de Investigaciones Biomédicas Uniremington, Facultad de Ciencias de la Salud, \\ Corporación Universitaria Remington (Uniremington), Calle 51 No. 51-27, Medellín 050010, Colombia; \\ jazmin.porras@uniremington.edu.co \\ 2 Grupo de Investigación en Remediación Ambiental y Biocatálisis (GIRAB), Instituto de Química, \\ Facultad de Ciencias Exactas y Naturales, Universidad de Antioquia UdeA, Calle 70 No. 52-21, \\ Medellín 050010, Colombia; yliceth.martinez@udea.edu.co (Y.L.M.-M.); yennytorres@usc.edu.co (Y.Á.-T.); \\ javier.silva@udea.edu.co (J.S.-A.) \\ * Correspondence: efraim.serna@uniremington.edu.co (E.A.S.-G.); ricardo.torres@udea.edu.co (R.A.T.-P.)
}

Citation: Serna-Galvis, E.A.; Martínez-Mena, Y.L.; Porras, J.; Ávila-Torres, Y.; Silva-Agredo, J.; Torres-Palma, R.A. Understanding the Role of Complexation of Fluoroquinolone and $\beta$-Lactam Antibiotics with Iron (III) on the Photodegradation under Solar Light and UVC Light. Water 2021, 13, 2603. https://doi.org/10.3390/w13182603

Academic Editor: Alexandre T. Paulino

Received: 23 August 2021

Accepted: 15 September 2021

Published: 21 September 2021

Publisher's Note: MDPI stays neutral with regard to jurisdictional claims in published maps and institutional affiliations.

Copyright: (c) 2021 by the authors. Licensee MDPI, Basel, Switzerland. This article is an open access article distributed under the terms and conditions of the Creative Commons Attribution (CC BY) license (https:// creativecommons.org/licenses/by/ $4.0 /)$.

\begin{abstract}
Antibiotics elimination by some photochemical processes involves ferric ions, but little is discussed about the fundamental aspects of complexation effects on their degradation. This study compares the photodegradation of two fluoroquinolones, three $\beta$-lactams, and their ferric complexes in deionized water. The complexed antibiotics were more recalcitrant than the free antibiotics to the solar light action (the photodegradation rate constants diminished by more than $50 \%$ ). To better study the photodegradation, other experiments considering two representative cases (ciprofloxacin and dicloxacillin) were performed. For ciprofloxacin, as the iron amount was increased from 0 to $7.5 \mu \mathrm{mol} \mathrm{L}{ }^{-1}$, its photodegradation rate constant decreased from 0.017 to $0.004 \mathrm{~min}^{-1}$. In contrast, for dicloxacillin, the increase in iron concentration (from 0 to $7.5 \mu \mathrm{mol} \mathrm{L}^{-1}$ ) accelerated its photodegradation (the rate constant augmented from 0 to $0.0026 \mathrm{~min}^{-1}$ ). When UVC light was used, the degradations of free and complexed antibiotics were very close, exhibiting values of degradation rate constants between 0.030 and $0.085 \mathrm{~min}^{-1}$. The antimicrobial activity (AA) was eliminated when $90 \%$ of ciprofloxacin and $90-95 \%$ of dicloxacillin were degraded. The AA removal was associated with structural changes in relevant moieties of antibiotics, such as fluorine and piperazyl ring for ciprofloxacin, or $\beta$-lactam ring for dicloxacillin.
\end{abstract}

Keywords: antimicrobial activity removal; antibiotics transformation; ferric complexes; photodegradation; solar light; UVC irradiation; water treatment

\section{Introduction}

Currently, antibiotics are recognized as contaminants of emerging concern. These substances are recalcitrant to conventional processes in municipal wastewater treatment plants [1]. Thereby, effluents of municipal treatment plants are one of the main routes of the discharge of antibiotics into the environment [1,2].

Highly consumed antibiotics, such as $\beta$-lactams and fluoroquinolone, are frequently found in the effluents of municipal wastewater treatment plants and environmental surface water. Indeed, ciprofloxacin (a fluoroquinolone) and cefalexin (a $\beta$-lactam) have been recently proposed as markers of antibiotic pollution in environmental water and municipal wastewater treatment plant effluents [3]. Nowadays, it is well-known that the continuous input of antibiotics into municipal wastewater treatment plants and environmental water becomes a risk factor for resistant bacteria proliferation [4-6]. Bacterial resistance to antibiotics represents a great threat to human health [7]. For instance, bacterial resistance 
to $\beta$-lactam and fluoroquinolone antibiotics has been observed in the environment, which can be transferred among different bacteria and even to humans $[8,9]$.

In environmental water, drinking water, or even in wastewater, the presence of metallic cations, such as iron, is common (III) [10,11]. Because of the presence of multiple functional groups containing alone pairs (e.g., carboxylic acid, amide, amine, ketone, reduced forms of sulfur) on the $\beta$-lactams and fluoroquinolones, these antibiotics can form complexes with cations of metals, such as ferric ions. The pharmacology field has studied the complexation of iron (III) with $\beta$-lactams and fluoroquinolones [12,13]. However, information about the degradation of these complexes promoted by solar light and/or UVC light in the environmental sciences is lacking. In fact, the complexation of ferric ions with $\beta$-lactams or fluoroquinolones can play a relevant role in the interaction of these antibiotics with solar light in environmental water. The study of the response of these kinds of complexes to light could be important for understanding the performance of advanced oxidation processes, such as photo-Fenton, sono-photo-Fenton, photo-electro-Fenton, and the activation of persulfate or peroxymonosulfate, which involve iron and light for the treatment of $\beta$ lactam or fluoroquinolone antibiotics [14-20]. While it is well-known that antibiotics have functional groups which are able to complex metallic species, these works did not consider the direct interaction between the organic pollutants and metal ions.

Although several studies deal with the (photo)-degradation of fluoroquinolone and $\beta$-lactam antibiotics by systems involving iron [18,21-23], there is little information about the effect of the complexation of these antibiotics by ferric ions, nor the implications of their photodegradation. Such works depict the degradation percentages of the antibiotic caused by the radical species action, but none quantify the interaction of ferric ions with the target pollutants and the role of complexation in the degradation. Only a recent study has considered the role of iron complexation in the photodegradation of enrofloxacin [17]. Nevertheless, this previous study is focused on treating an antibiotic solely; and, the effect of iron concentration on the degradation of the complex, or the type of light, is not evaluated. Furthermore, data about the evolution of antimicrobial activity during the treatments is not presented.

This research aimed to understand the fundamental aspects of the effect of the complexation of fluoroquinolone and $\beta$-lactam antibiotics with ferric ions on photodegradation from solar and UVC light. In this study, novel aspects (which have not been considered in previous studies), such as the influence of the antibiotic class, iron concentration, and light-type on the photodegradation of the complexes, were studied. Additionally, the evolution of antimicrobial activity and its connection with primary transformations (other topics missed in the single previous work about the photochemical treatment of a ferric complex with antibiotics) were studied. Herein, the photodegradation of ferric complexes of five highly consumed antibiotics was assessed. Initially, the stoichiometric ratio of the ferric complexes of the target antibiotics in aqueous media was established. Secondly, the degradation of both free and complexed antibiotics under simulated solar irradiation was tested. Two representative molecules from the treatment with solar light were selected (ciprofloxacin and dicloxacillin), which had different behaviors. Then, the effect of iron concentration and the change of solar light by UVC was evaluated. Afterward, the primary transformations induced by the photo-treatment on the representative antibiotics were discussed. Moreover, the evolution of the antimicrobial activity during the photodegradation was determined, along with its connection to the structural transformations of the representative antibiotics. The results from our work could be valuable to the understanding of the photostability of ferric complexes of fluoroquinolones and $\beta$-lactams under sunlit environmental water, or the action of advanced oxidation processes (AOPs) involving iron and solar light or UVC light. 


\section{Materials and Methods}

\subsection{Reagents}

Ciprofloxacin and norfloxacin were provided by Laproff laboratories (Medellín, Colombia). Cefalexin, dicloxacillin, and cloxacillin were provided by Syntofarma (Medellín, Colombia). Acetonitrile, Iron (III) chloride hexahydrate, hydrochloric acid, sodium chloride, and sodium hydroxide were purchased from Merk (Darmstadt, Germany). Formic acid was obtained from Carlo Erba (Barcelona, Spain). Nutrient Agar, tryptone type I, and yeast extract powder were provided by HiMedia (Mumbai, India); the culture media and broths were sterilized at $121^{\circ} \mathrm{C}$ using an SA-300H Sturdy autoclave (New Taipei, Taiwan). All solutions were prepared using deionized water obtained from a Barnstead Smart2Pure Thermo Scientific apparatus (Bartlesville, OK, USA).

Ciprofloxacin and norfloxacin were selected as representative fluoroquinolones because they are frequently found in raw water, tertiary effluents of municipal wastewater treatment plants (MWTP), and surface water [24,25]. Furthermore, these fluoroquinolones have a high antibiotic potency [26,27], and they can negatively impact the environment through bacterial resistance development and a toxic effect on aquatic species $[24,25,28]$. Cefalexin, dicloxacillin, and cloxacillin were chosen as target $\beta$-lactams due to their high consumption and elevated excretion through urine as unchanged forms; additionally, they have been detected in effluents of MWTP and environmental water, and negatively impact aquatic systems $[3,29,30]$.

\subsection{Reaction Systems}

A beaker containing $50 \mathrm{~mL}$ of the sample to be treated was placed under the irradiation source, and it was stirred magnetically. For photodegradation using solar light, an Original Hanau Suntest (Hanau, Germany) was used (the actual photon flux in the reaction beaker: $1.4 \times 10^{17}$ photons s$^{-1}$, which was measured by actinometry using ferrioxalate) [31]. For the treatment of the pollutants using UVC light, we used a homemade reflective reactor covered inside with aluminum foils and equipped with an Osram Puritec (HNS G5, 8W) lamp (Wilmington, MA, USA), having the main emission peak at $254 \mathrm{~nm}$ (the actual photon flux in the reaction beaker was $3.2 \times 10^{16}$ photons $\mathrm{s}^{-1}$; this was also determined by actinometry using ferrioxalate) [31]. As the main focus of our work was on the comprehension of fundamental aspects, the degradations of the antibiotics and their ferric complexes were performed in deionized water. All experiments were carried out at least by duplicate, and the reported data are the mean values, and the error bars correspond to the standard deviations among replicates. This manner of presenting our results allows us to easily compare if the average values reported in the figures or tables are statistically similar, or different. The average values are similar when the error bars intercept them, and the average values are different if the error bars have no interception.

\subsection{Analyses}

The formation of complexes was established using an Orion AquaMate 8000 Thermo Scientific spectrophotometer (Bartlesville, OK, USA). The absorption spectra were measured from 190 to $700 \mathrm{~nm}$. The degradations of the free antibiotics and their respective complexes with ferric ions were followed by liquid chromatography using a UHPLC Focused UltiMate 3000 equipped with a DAD detector and a C-18 Hypersil GOLDTM column $(150 \times 4.6 \mathrm{~mm} ; 5 \mu \mathrm{m})$ (Thermo Scientific, Bartlesville, OK, USA). In all cases, $20 \mu \mathrm{L}$ was the injection volume, and as for the mobile phase, a mixture of acetonitrile and formic acid at $10 \mathrm{mmol} \mathrm{L}^{-1}$ was used. The specific chromatographic conditions for each antibiotic are summarized in Table 1. 
Table 1. Chromatographic conditions for the following to the degradation of the target antibiotics.

\begin{tabular}{|c|c|c|c|}
\hline Antibiotic & $\begin{array}{l}\text { Acetonitrile/Formic Acid } \\
\qquad(\% / \%)\end{array}$ & $\begin{array}{l}\text { Detection Wavelength } \\
\text { (nm) }\end{array}$ & $\begin{array}{c}\text { Flow } \\
\left(\mathrm{mL} \mathrm{min}^{-1}\right)\end{array}$ \\
\hline $\begin{array}{c}\text { Ciprofloxacin } \\
\text { (CIP) }\end{array}$ & $15 / 85$ & 278 & 0.6 \\
\hline $\begin{array}{l}\text { Norfloxacin } \\
\text { (NOR) }\end{array}$ & $15 / 85$ & 280 & 0.6 \\
\hline $\begin{array}{l}\text { Cefalexin } \\
\text { (CFX) }\end{array}$ & $20 / 80$ & 260 & 0.5 \\
\hline $\begin{array}{l}\text { Dicloxacillin } \\
\text { (DCX) }\end{array}$ & $50 / 50$ & 225 & 0.5 \\
\hline $\begin{array}{l}\text { Cloxacillin } \\
\text { (CLX) }\end{array}$ & $50 / 50$ & 225 & 0.5 \\
\hline
\end{tabular}

The actual intensities in the reaction systems were determined by actinometry using ferrioxalate (at $0.006 \mathrm{~mol} \mathrm{~L}^{-1}$ ). This method comprises the photoreduction of iron (III), and the generated iron (II) is quantified by complexation with 1,10-phenanthroline [31].

The evolution of antimicrobial activity was analyzed by the diffusion agar method [32], using $50 \mu \mathrm{L}$ of the sample S. aureus (ATCC 25923) as indicator microorganism, and the incubation was performed in a HeraTherm Thermo Scientific Incubator at $37^{\circ} \mathrm{C}$ during $24 \mathrm{~h}$.

The primary transformation products were established using an HPLC Agilent 1200 series coupled to an Agilent LC/MSD VL SQ mass spectrometer (Santa Clara, CA, USA). The column and mobile phase were operated at the conditions presented in Table 1 . The injection volume was $10 \mu \mathrm{L}$ and the mass spectrometer detector was operated in positive ion mode [18].

\section{Results}

\subsection{Ability of the Target Antibiotics to Form Complexes with Ferric Ions}

Initially, to establish the stoichiometry of the complexes, the absorbance (at a wavelength of maximum absorption of the complex) at different antibiotic/ferric ratios was measured. The change absorbance at the selected wavelength was followed until achieving a plateau. The point at which the plateau was reached indicated the stoichiometric ratio [17].

\subsection{Response of the Antibiotics and Their Ferric Complexes to Solar Light}

Figure S1 (in the Supplementary Material) illustrates the case of ciprofloxacin for the stoichiometric relationship determination. For the CIP-ferric ion complex, when the CIP/ Fe (III) ratio changed from 1 to 2 , the absorbance at $430 \mathrm{~nm}$ increased from $\sim 0.16$ to $\sim 0.32$. Then, a plateau (approximately) was reached, indicating that this complex is formed with two molecules of CIP per one ion of Fe (III). A similar procedure was applied to the other target antibiotics, and all the results are summarized in Table 2.

Table 2. Stoichiometric relationships for the complexes between the target antibiotics and the ferric ion.

\begin{tabular}{|c|c|c|c|c|}
\hline Antibiotic & $\begin{array}{l}\text { pKa of the Free } \\
\text { Antibiotic }\end{array}$ & $\begin{array}{c}\text { Maximum Wavelength of the } \\
\text { Complex Absorption } \\
(\mathrm{nm})^{1}\end{array}$ & $\begin{array}{l}\text { Stoichiometric Relationship } \\
\text { forAntibiotic-Iron (III) } \\
\text { Complex }\end{array}$ & $\begin{array}{l}\text { The Same Relationship } \\
\text { Was Reported by }\end{array}$ \\
\hline Ciprofloxacin (CIP) & $\begin{array}{l}\mathrm{pKa}_{1}: 6.2 \\
\mathrm{pKa}_{2}: 8.8\end{array}$ & 435 & $2-1$ & {$[33,34]$} \\
\hline Norfloxacin (NOR) & $\begin{array}{l}\mathrm{pKa}_{1}: 6.3 \\
\mathrm{pKa}_{2}: 8.7\end{array}$ & 430 & $2-1$ & [33] \\
\hline Cefalexin (CFX) & $\begin{array}{l}\mathrm{pKa}_{1}: 5.2, \\
\mathrm{pKa}_{2}: 7.3\end{array}$ & 360 & $1-1$ & 2 \\
\hline Dicloxacillin (DCX) & pKa: 2.8 & 355 & $1-1$ & [12] \\
\hline Cloxacillin (CLX) & pKa: 2.7 & 355 & $1-1$ & [34] \\
\hline
\end{tabular}

${ }^{1}$ See the UV-vis spectra of the free and complexed antibiotics in Figures S2 and S3. ${ }^{2}$ Not reported. 
The degrading action of solar light on the ferric complexes of the antibiotics was evaluated. The photolysis of the free antibiotics from the solar light was also assessed. The pseudo-first-order photolysis rate constants $(\mathrm{k})$ were calculated, and the results are depicted in Figure 1.

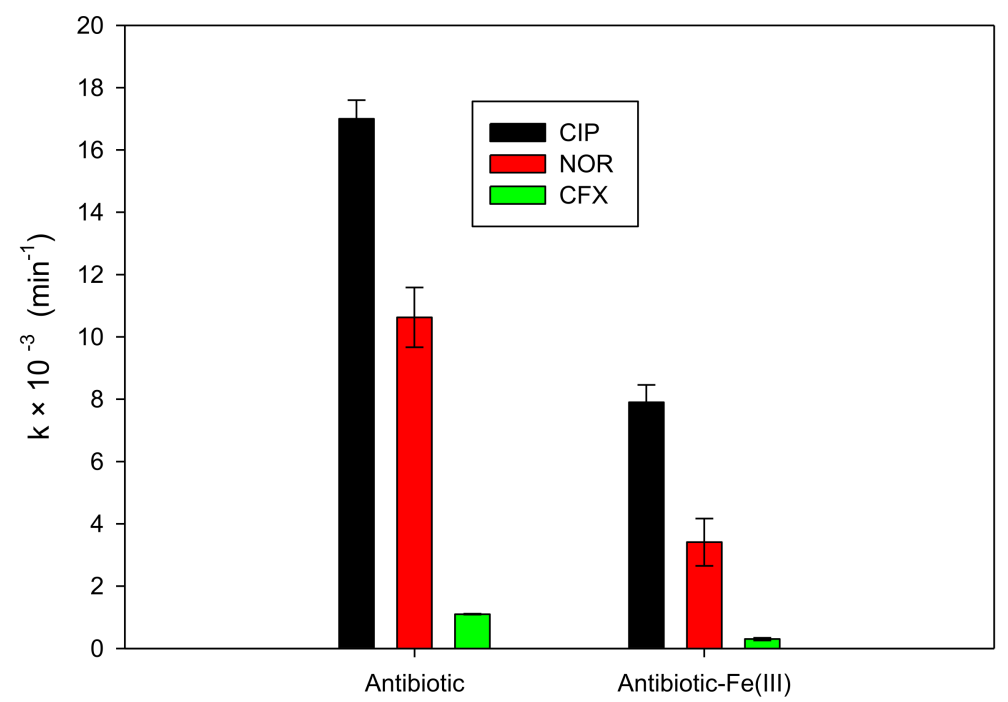

Figure 1. Pseudo-first order rate constants (k) for the degradation of antibiotics and their ferric complexes under simulated solar light. Experimental conditions: [Antibiotic]: at the stoichiometric ratio with Fe (III), [Fe (III)]: $2.5 \mu \mathrm{mol} \mathrm{L}^{-1}, \mathrm{pH}_{\text {initial }}$ 6.0. Note: DCX, CLX, and their ferric complexes had no photodegradation; i.e., the $\mathrm{k}$ values were zero.

\subsection{Effect of Iron Concentration on the Photodegradation by Solar Light}

The environmental concentration of the ferric ions varies depending on the nature of the water $[10,11]$. Then, the role of the iron concentration on the degradation should be evaluated. To test the effect of ferric ions amount, CIP and DCX were chosen as representative cases. This selection was based on the results in Figure 1, where CIP exhibited the highest and DCX had no photolysis.

Three iron concentrations were considered: zero, the stoichiometric concentration of ferric ion required to complex the antibiotic, and 3-folds the stoichiometric concentration of ferric ion for the complex formation. Table 3 contains the k-values of the solar photodegradation of CIP and DCX for the effect of the amount of the ferric ion.

Table 3. Effect of iron concentration on the degradation of ciprofloxacin (CIP) and dicloxacillin (DCX).

\begin{tabular}{|c|c|}
\hline \multicolumn{2}{|l|}{ CIP } \\
\hline Conditions $^{1}$ & $\mathrm{k} \times 10^{-3}\left(\min ^{-1}\right)$ \\
\hline \multicolumn{2}{|l|}{ DCX } \\
\hline Conditions & $\mathrm{k} \times 10^{-3}\left(\mathrm{~min}^{-1}\right)$ \\
\hline$[\mathrm{CIP}]: 5.0 \mu \mathrm{mol} \mathrm{L}-1$ & $17.0 \pm 0.6$ \\
\hline [CIP]: $5.0 \mu \mathrm{mol} \mathrm{L}-1 /[\mathrm{Fe}(\mathrm{III})]: 2.5 \mu \mathrm{mol} \mathrm{L}^{-1}$ & $7.9 \pm 0.5$ \\
\hline$[\mathrm{CIP}]: 5.0 \mu \mathrm{mol} \mathrm{L}{ }^{-1} /[\mathrm{Fe}(\mathrm{III})]: 7.5 \mu \mathrm{mol} \mathrm{L}^{-1}$ & $4.0 \pm 0.3$ \\
\hline$[\mathrm{DCX}]: 2.5 \mu \mathrm{mol} \mathrm{L}-1$ & $0.0 \pm 0.0$ \\
\hline [DCX]: $2.5 \mu \mathrm{mol} \mathrm{L}^{-1} /[\mathrm{Fe}(\mathrm{III})]: 2.5 \mu \mathrm{mol} \mathrm{L}^{-1}$ & $0.0 \pm 0.0$ \\
\hline [DCX]: $2.5 \mu \mathrm{mol} \mathrm{L}^{-1} /[\mathrm{Fe}(\mathrm{III})]: 7.5 \mu \mathrm{mol} \mathrm{L}^{-1}$ & $2.6 \pm 0.1$ \\
\hline
\end{tabular}

${ }^{1}$ All experiments were performed at $\mathrm{pH}_{\text {initial }} 6.0$.

\subsection{Effect of Changing Solar Light by UVC Irradiation}

Once the ability of solar light to degrade the ferric complexes of the antibiotics was established, the response to the UVC light (the other light type commonly used in the AOPs) 
was tested. Then, the two representative compounds (CIP and DCX), and their respective ferric complexes, were treated using UVC, and their pseudo-first-order kinetic constants (k) were determined (Figure 2). Additionally, the ratios (R) between the constants were calculated using Equation (1) and compared with the $\mathrm{R}$ values obtained for the treatment with solar light (Table S1).

$$
\mathrm{R}=\mathrm{k}_{\text {complex }} / \mathrm{k}_{\text {free antibiotic }}
$$

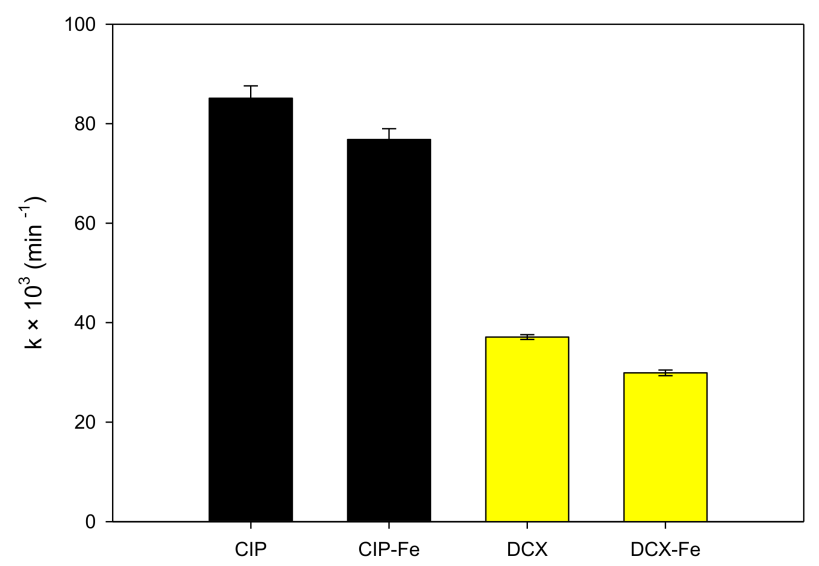

Figure 2. Pseudo-first order rate constants (k) for the degradation of the two representative antibiotics (CIP and DCX) and their ferric complexes by UVC irradiation. Experimental conditions: [CIP]: $5.0 \mu \mathrm{mol} \mathrm{L}^{-1} /\left[\mathrm{Fe}\right.$ (III)]: $2.5 \mu \mathrm{mol} \mathrm{L}-1$, [DCX]: $2.5 \mu \mathrm{mol} \mathrm{L}^{-1} /\left[\mathrm{Fe}\right.$ (III)]: $2.5 \mu \mathrm{mol} \mathrm{L}^{-1}$; $\mathrm{pH}_{\text {initial }} 6.0$.

\subsection{Primary Transformations of the Antibiotics and Their Iron Complexes under Light Action}

In the case of CIP, both the simulated solar irradiation and UVC light were able to promote the degradation of the free antibiotic and its ferric complex. Then, to understand the initial changes induced by these irradiations to this antibiotic, as well as its ferric complex, the primary transformation products were established using HPLC-MS. Three stable initial products (named P1, P2, and P3) were identified (Figure 3).<smiles>O=C(O)c1cn(C2CC2)c2cc(N3CCNCC3)c(F)cc2c1=O</smiles>

CIP<smiles>NCCNc1ccc2c(=O)c(C(=O)O)cn(C3CC3)c2c1</smiles>

P2<smiles>O=C(O)c1cn(C2CC2)c2cc(N3CCNCC3)c(O)cc2c1=O</smiles>

P1<smiles>O=C(O)c1cn(C2CC2)c2cc(N3CCN(O)CC3)c(O)cc2c1=O</smiles>

\section{.}

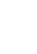


3.6. Antimicrobial Activity Evolution during the UV Light Action on the Antibiotics and Their Iron Complexes

Another important parameter to consider during the degradation of antibiotics is the change in antimicrobial activity (AA). This aspect has a great environmental impact $[35,36]$. As UVC light induced stronger photo-degradations of the selected antibiotics and their complexes (see Figures 1 and 2), this light was used to perform the experiments related to the AA. The evolution of AA for CIP and DCX treated in the absence and presence of ferric ions using the UVC irradiation was followed (Figure 4).

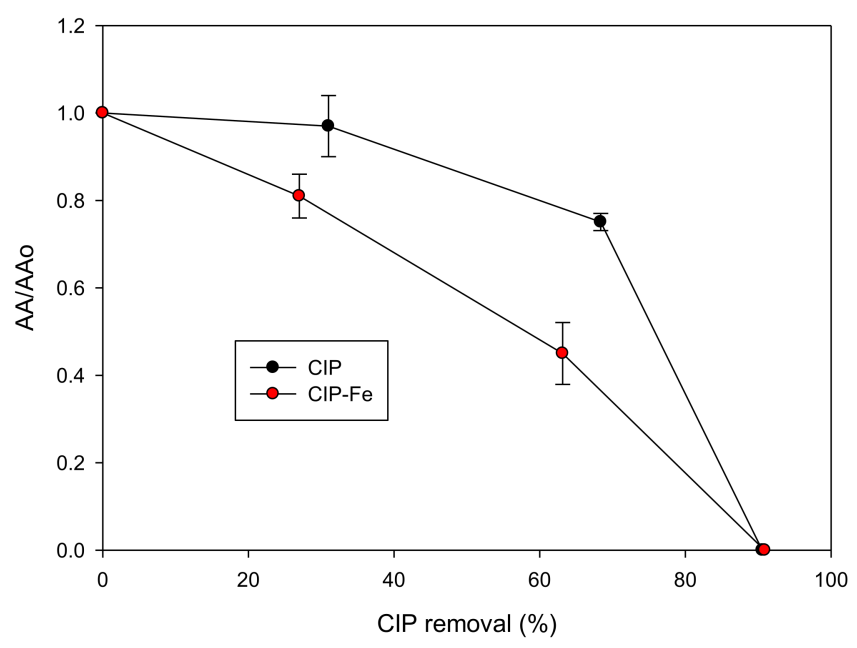

(a)

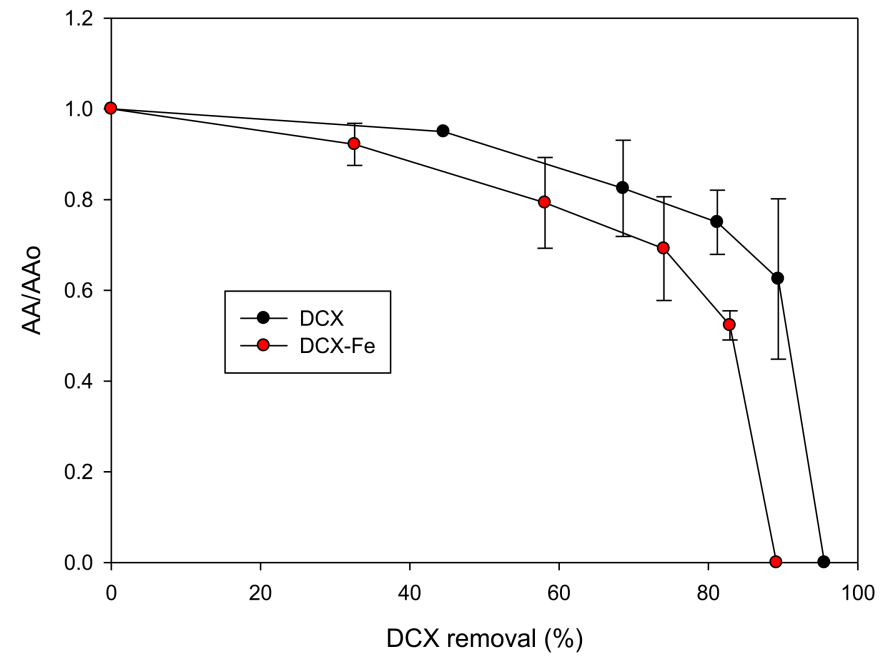

(b)

Figure 4. Antimicrobial activity (AA) evolution for CIP (a) and DCX (b) and their ferric complexes under the UVC action. Experimental conditions: [CIP]: $5.0 \mu \mathrm{mol} \mathrm{L}{ }^{-1} /\left[\mathrm{Fe}\right.$ (III)]: $2.5 \mu \mathrm{mol} \mathrm{L}^{-1}$, [DCX]: $2.5 \mu \mathrm{mol} \mathrm{L}^{-1} /\left[\mathrm{Fe}\right.$ (III)]: $2.5 \mu \mathrm{mol} \mathrm{L}^{-1} ; \mathrm{pH}_{\text {initial }} 6.0$.

\section{Discussion}

\subsection{Complexes Formation and Their Stoichiometric Relationships}

The results in Table 2 showed that, at the experimental conditions, the CIP-Fe ${ }^{3+}$ complex has a 2-1 stoichiometric relationship. Also, the complex of NOR with the ferric ion has a 2-1 stoichiometric relationship (Table 2). Our results were consistent with the 2-1 stoichiometric relationships reported in the literature previously for CIP and NOR [33,37]. For the two fluoroquinolones, the antibiotic-ferric ions mixture showed a new band between 
400 and $600 \mathrm{~nm}$ (Figure S2). Additionally, for the mixture of the fluoroquinolone antibiotics and the ferric ions, an intense yellow color appeared in the solution (as exemplified for CIP in Figure S4). These facts indicated the formation of complexes between the iron (III) and the evaluated fluoroquinolones (CIP and NOR) $[17,38]$. The piperazine ring and the ketocarbonyl moiety on the fluoroquinolones are most likely binding sites for the complexation of the ferric ion [39]. At the experimental $\mathrm{pH}(\sim 6.0)$, the target fluoroquinolones were mainly in their cationic form (with both the piperazyl and carboxylic groups protonated, as shown in Figure S5). It can be noted that the keto-carbonyl moiety has a higher number of lone electron pairs than the protonated nitrogen on the piperazine ring. This favors the interaction between the fluoroquinolones and the ferric ion through chelation of the metal by the contiguous ketone and carboxyl groups [38-40], which is consistent with the 2-1 stoichiometric relationship where two molecules of fluoroquinolone complexed a ferric ion.

In the case of the $\beta$-lactam antibiotics, at the tested experimental conditions, these antibiotics showed 1-1 stoichiometric relationships (Table 2). In fact, the 1-1 stoichiometric relationship is very common in the complexes with penicillins and cephalosporins due to their ability to simultaneously interact through multiple sites with the metal cations [12,41]. We can mention that for the antibiotic-ferric ions mixtures, the absorption increased above $330 \mathrm{~nm}$ (Figure S3). Moreover, a small shoulder was found between 340 and $380 \mathrm{~nm}$. These spectral aspects denoted the formation of the $\beta$-lactam-ferric ion complexes. Indeed, penicillins and cephalosporins complex metallic cations through chelates involving carboxyl group and the amide moiety on the $\beta$-lactam ring $[12,41,42]$. At the experimental $\mathrm{pH}(\sim 6.0)$, the carboxylic acid group on all the considered $\beta$-lactam antibiotics were deprotonated (Figure S6), which favors their interaction with the ferric ions.

A general aspect of all the antibiotic-ferric ion complexes formed herein is their ability to absorbs light from 300 to $600 \mathrm{~nm}$ (Figures S2 and S3), which is associated with a charge transfer between the antibiotics and the metal ion, and the $\mathrm{d}-\mathrm{d}$ transitions of the iron $[38,43]$. These absorptions in the visible range (i.e., wavelengths $>400 \mathrm{~nm}$ ) are responsible for the colored nature of the complexes [33], as observed in Figure S4.

We should mention that the information presented in our work provides an initial approach to the formation of ferric complexes of antibiotics in water. Then, in future works, it is recommended to perform more specialized analyses (e.g., infrared, proton, and carbon nuclear magnetic resonance) to confirm the functional group on antibiotics acting as the chelators, geometric structure, and spectroscopic properties of the complex.

\subsection{Response of the Complex to the Simulated Solar Light}

As indicated in the caption for Figure 1, under our working conditions, DCX and CLX, and their corresponding complexes, did not exhibit photolysis by the solar light. At the same time, the photolysis for the complexes of CIP, NOR, and CPX was lower (approximately a half) than that observed for the free antibiotics. The results indicate that, despite their higher light absorption for the complexed antibiotics (Figures S2 and S3), the complexes are less prone to solar light action than the corresponding free antibiotics (Figure 1). This is because the metal withdraws electron density from the ligands (i.e., the antibiotics), relocating part of electron density/charges from the organic structure on the metal ion, leading to electronic transitions with an energy gap lower than that needed for the free metal [44]. This generates absorptions at longer wavelengths (e.g., the visible range) as shown in the spectra (Figures S2 and S3). Meanwhile, as the antibiotics lose electron density, the photo-degradation (which depends on available electron density on the compounds) of the complexed antibiotics is diminished with regards to their free forms (Figure 1).

Indeed, it is reported that the electron density withdrawing by the ferric ion augments the activation energy for the cleavage and formation of bonds on the ligands. For instance, previous theoretical works on the complexation of fluoroquinolones have demonstrated that the interaction of these antibiotics with the metal cations increases the activation energy for some photodegradation pathways [44-46]. Besides, the interaction of solar light with 
the fluoroquinolones induces a self-photosensitization process forming reactive oxygen species (ROS), such as singlet oxygen, but this pathway is also affected by the complexation (these aspects are detailed in Section 4.5).

On the other hand, it is noted that sunlight induces the direct photodegradation of cephalosporins through decarboxylation and the rupture of the $\beta$-lactam ring [47]. As the complexation of the ferric ion by this class of antibiotics involves their carboxylic group and $\beta$-lactam ring (Figure S6) [12], such photodegradation pathways are limited for the complexed cephalosporin. Consequently, a diminishing of the degradation rate constant by the complexation of CFX was found (Figure 1).

\subsection{Effect of the Iron Concentration}

From Table 3, it can be observed that as the concentration of ferric ion is higher, its photodegradation rate constant for CIP decreased from $17.0 \times 10^{-3} \mathrm{~min}^{-1}$ to $4.0 \times 10^{-3} \mathrm{~min}^{-1}$. On the contrary, since $\beta$-lactam as the concentration of iron is higher, the $k$ value is augmented from $\sim 0$ to $2.6 \times 10^{-3} \mathrm{~min}^{-1}$. The results for CIP are coincidental with those reported by Wei et al. [44]. They also found that the photodegradation of this fluoroquinolone by solar light was diminished as the ferric ion concentration increased. However, these authors did not explain such results. Thereby, to understand this finding, it is necessary to consider the information provided by the spectra of the solutions at the different amounts of iron. Figure S7 shows that the absorbance for the mixtures of CIP and ferric ions, between 290 and $500 \mathrm{~nm}$, is strongly altered as the iron concentration increased. The spectrum at the $3 \mathrm{Fe}$ condition suggests that absorbance at the $290-500 \mathrm{~nm}$ range can be predominantly associated with the excess of iron. Thus, it is proposed that, in addition to the complexation, which decreases the photolysis as above shown, when the ferric ion is in excess, this substance competes with the photons, affecting the photolytic process of the complex.

In the case of the representative $\beta$-lactam, the spectra for the mixtures of DCX and the ferric ion show that the absorbance between 260 and $400 \mathrm{~nm}$ is also augmented as the iron concentration is higher (Figure S8). Furthermore, the high absorbance at the highest concentration of ferric ions was associated with the excess of the metal ion. Then, in such conditions, there is a predominance of the aqua-complexes of ferric ion, which can be decomposed by the solar light, generating hydroxyl radicals (Equation (2), [48]). Consequently, the produced hydroxyl radical attacks the complex (which had no photolysis, Figure 1), accelerating the DCX removal, as reported in Table 3. Although, in the case of CIP and in excess of iron, the action of the radical produced through Equation (2) is also possible, as the $\mathrm{HO}^{*}$ formation competes with the photolytic route, affecting the removal rate of this antibiotic, as explained above.

$$
\mathrm{Fe}^{3+}+\mathrm{H}_{2} \mathrm{O}+\text { solar light } \rightarrow \mathrm{Fe}^{2+}+\mathrm{HO}^{*}+\mathrm{H}^{+}
$$

The effect of iron amount indicates that, in a water sample where the ferric ion concentration is higher than CIP, the photodegradation of this fluoroquinolone is diminished by complexation and shielding by the iron species. Meanwhile, for antibiotics, such as DCX, which have no significant photolysis, high ferric ion amounts favor their degradation due to the formation and action of hydroxyl radical coming from the photodecomposition of the ferric aqua-complexes. Indeed, further research should verify the role of $\mathrm{HO}^{*}$ on the degradation of antibiotics through its reaction with a radical scavenger (e.g., tert-butanol), or the development of electron spin resonance (ESR) analyses.

\subsection{Degradation under UVC Irradiation}

Figure 2 shows that the $k$-values of photodegradation of the free antibiotic, and its corresponding ferric complexes by the UVC action, were closer among them. Indeed, the $R$ values for the photolytic process using UVC were very close to one and higher than the $R$ values for the photodegradation using solar light (Table S1). 
As mentioned above, the activation energy required to cleavage or form a bond on the complexed antibiotics is higher than that needed for the free antibiotics [44]. Then, the wavelengths of the solar light have a limited capability to degrade the antibiotic-ferric ion complexes. However, when these complexes are irradiated with UVC light, these photons with shorter wavelengths have a higher energy than the photons from the solar light (Table S3), and the energy provided by the UVC light is enough to promote the degradation of the free antibiotics and their ferric complexes.

\subsection{Primary Transformations of the Antibiotics}

Three primary products (Figure 3) were identified during the degradation of both free and complexed CIP using UVC light (as evidenced from the corresponding chromatograms presented in Figure S9). The P1 product has a hydroxyl moiety in the place of the fluorine atom in CIP. The P1 formation can be rationalized considering a photo-substitution mechanism. This is the main pathway of direct photodegradation of fluoroquinolones [39,49-52]. According to the literature, the light $(h v)$ changes CIP from its ground state $\left({ }^{1} \mathrm{CIP}\right)$ to a singlet excited state $\left({ }^{1} \mathrm{CIP} *\right.$, Equation $\left.(3)\right)$, which goes to a triplet excited state $\left({ }^{3} \mathrm{CIP}^{*}\right.$, Equation (4)). Then, ${ }^{3} \mathrm{CIP}^{*}$ is attacked by the nucleophilic hydroxyl anion (from water), releasing the fluorine atom to form P1 (Equation (5), and Figure S11) [53].

$$
\begin{gathered}
{ }^{1} \mathrm{CIP}+h v \rightarrow{ }^{1} \mathrm{CIP}^{*} \\
{ }^{1} \mathrm{CIP}^{*} \rightarrow{ }^{3} \mathrm{CIP}^{*} \\
{ }^{3} \mathrm{CIP}^{*}+\mathrm{H}_{2} \mathrm{O} \rightarrow \mathrm{P} 1+\mathrm{F}^{-}+\mathrm{H}^{+}
\end{gathered}
$$

The P2 product presents a hydrogen atom in place of a fluorine atom, in addition to a rupture of the piperazyl ring. It is noted that the interaction of the fluoroquinolones with light also promotes reductive dehalogenation [50], which supports the generation of P2. Previous studies have demonstrated that fluoroquinolones generate singlet oxygen and superoxide radical anion through a self-sensitization mechanism. In fact, ${ }^{3} \mathrm{CIP}^{*}$ can interact with the dissolved oxygen, transferring energy from the ${ }^{3} \mathrm{CIP}^{*}$ to the ground-state of oxygen $\left({ }^{3} \mathrm{O}_{2}\right)$ to produce singlet oxygen $\left({ }^{1} \mathrm{O}_{2}\right.$, Equation (6)), and/or transferring an electron from ${ }^{3} \mathrm{CIP}^{*}$ to ${ }^{3} \mathrm{O}_{2}$ to form superoxide radical anion $\left(\mathrm{O}_{2}{ }^{\bullet-}\right)$ and a cation radical of CIP (Equation (7)) [39,50-52]. Singlet oxygen and superoxide anion radical (ROS) are oxidizing agents able to attack the secondary amine on the piperazyl ring of the defluorinated CIP through an oxidative pathway (Figure S10), forming a cation radical centered on the amine group. This then reacts with water to produce intermediate hydroxylamine, which evolves toward an imine. Subsequently, the imine is hydrolyzed to form P2 (Figure S10) [36,53].

$$
\begin{gathered}
{ }^{3} \mathrm{CIP}^{*}+{ }^{3} \mathrm{O}_{2} \rightarrow{ }^{1} \mathrm{CIP}+{ }^{1} \mathrm{O}_{2} \\
{ }^{3} \mathrm{CIP}^{*}+{ }^{3} \mathrm{O}_{2} \rightarrow \mathrm{CIP}^{+\bullet}+\mathrm{O}_{2}^{\bullet-}
\end{gathered}
$$

The P3 product shows a hydroxyl moiety in the place of the fluorine atom and another hydroxyl group on the secondary amine of the piperazyl. The formation of this product can be explained considering the photo-substitution at the aromatic ring on CIP, plus the attack of the ROS, such as singlet oxygen or superoxide radical anion to the piperazyl group in CIP or P1. As mentioned above, the ROS react with the secondary amine on the piperazyl ring, generating a cation radical on this amine, which interacts with water to produce P3 (Figure S10) [36,53].

The identified primary products from the photo-degradation for free and complexed CIP were the same (Figure S9). However, the formation from the complexed antibiotic was lower than the obtained from the free antibiotic (Figure S11). As reported by Wei et al., the complexation of CIP with the ferric ion modifies both the strength of the C-F bond and the energy for the $\mathrm{HO}^{-}$addition [44], thus affecting the photo-substitution pathway that leads to the formation of P1. Besides, the singlet oxygen generation can be diminished when the CIP is complexed; the physical quenching of ${ }^{3} \mathrm{CIP}^{*}$ (Equation (8), [39]) may predominate on 
the energy transfer (Equation (6)) [54]. Furthermore, the reactivity of CIP toward the ROS decreased due to a diminution of the electron density on the complexed fluoroquinolone, which limits the oxidative pathway on the piperazyl ring [44] that lead to the generation of $\mathrm{P} 2$ and $\mathrm{P} 3$.

$$
{ }^{3} \mathrm{CIP}^{*}+{ }^{3} \mathrm{O}_{2} \rightarrow{ }^{1} \mathrm{CIP}+{ }^{3} \mathrm{O}_{2}+\text { heat }
$$

On the other hand, Figure 2 shows that the photodegradation of the ferric complex of DCX under UVC was lower than the free antibiotic. Therefore, the formation of photoproducts may be different from that for the complexed DXC. However, to understand the transformations of DCX under the UVC light action, the experimental elucidation of primary products using LC-MS techniques in future researches is strongly recommended.

\subsection{Antimicrobial Activity Evolution}

Before discussing the evolution of AA, it is important to analyze the response of the indicator microorganism (S. aureus) against the free and complexed antibiotics, without the photo-treatment (Figure S12). We can remark that the AA for the complexed antibiotic was slightly lower than the free antibiotic. This result can be rationalized considering that the complexation of the antibiotics with the iron can decrease the permeation into bacterial cells, and/or diminish the interaction with target sites inside the microorganisms [55]. Indeed, our results are consistent with the literature on the complexation of fluoroquinolones, which reports that the chelation of CIP with metal cations decreases the AA $[13,55,56]$. Similarly, previous studies on $\beta$-lactam antibiotics have also shown that their complexation with ferric ion declines the AA, possibly due to modifications of steric, electronic, and pharmacokinetic factors, along with changes in the action mechanism on the bacteria [12,57-59].

From Figure 4, it can be noted that the treatment with UVC light was able to eliminate the AA associated with both the free antibiotics and their ferric complexes (Figure 4). The elimination of the AA was linked to the transformations of antibiotics. As Figure 3 shows, the UVC light induced a fluorine replacement on the free CIP molecule and its complexed form (see P1 and P2), in addition to changes in the piperazyl moiety by the ROS action (see P2 and P3). It is reported that the fluorine atom on the fluoroquinolones plays a determinant role in inhibiting the DNA gyrase (which is the action mode of CIP on bacteria [60]) and controlling the cell permeation [61]. Moreover, the modifications on the piperazyl ring alter the acid/base speciation of CIP and decrease the lipophilicity, diminishing the cell permeability [61]. Hence, the fluorine loss and piperazyl rupture justify the AA removal observed in Figure 4a.

In the case of DCX and its complex, the resultant solution from the treatment with the UVC had no AA against the indicator microorganism (Figure $4 \mathrm{~b}$ ). Indeed, the AA removal suggests the photo-treatment using UVC could modify relevant moieties (e.g., $\beta$-lactam ring) on DCX responsible for the antimicrobial activity toward bacteria [35].

\section{Conclusions}

The six target antibiotics were able to form complexes with ferric ions, and different antibiotic/iron stoichiometric relationships were found, indicating a high dependence on the antibiotic class and structure to act as ligand. The complexation increased the absorbance in the UVA range for the $\beta$-lactam antibiotics, which generated new absorption bands in the visible range for the fluoroquinolones. However, the degradation rate constants for the organometallic complexes under solar light were decreased regarding the free antibiotic. This indicates that the complexed antibiotics are more photostable than the free molecule, which is relevant for the comprehension of the environmental behavior of antibiotics.

For ciprofloxacin, as the iron amount was increased, its photodegradation using solar light decreased. On the contrary, for dicloxacillin, the increase in iron concentration accelerated its solar photodegradation. Such aspects can be useful to discuss results on advanced oxidation processes that deal with the degradation of antibiotics through systems involving iron. 
The photodegradation using UVC light was less sensitive to complexation due to this light of short wavelengths that have enough energy to promote transformations of both free and complexed antibiotics. The analyses of primary transformations for the UVC action on the representative antibiotic ciprofloxacin (fluoroquinolone), and its ferric complex, showed that despite the products are the same, their accumulation is lower for the complexed antibiotic. Additionally, the products of the ciprofloxacin demonstrated that the photodegradation using UVC led to the antibiotic defluorination and modifications of the piperazyl ring, which contributes to the elimination of the antimicrobial activity. Similarly, the action of UVC on dicloxacillin (a representative $\beta$-lactam) led to the removal of the antimicrobial activity, indicating a positive effect of this treatment toward mitigation of antibiotic resistance. Thus, photochemical processes, based on the use of UVC light, represent a good alternative for the degradation of fluoroquinolones, $\beta$-lactams, and their ferric complexes to decrease their AA.

Finally, it is important to remark that the degradations presented above were performed in pure water to understand fundamental aspects of the complexation of the target antibiotics. However, future studies must focus on evaluating the treatment of the ferric complexes of antibiotics in matrices such as sewage water, the effluents of municipal wastewater treatment plants, or environmental water, to study the effects of the water composition on the photodegradation of antibiotics and their ferric complexes.

Supplementary Materials: https:/ /www.mdpi.com/article/10.3390/w13182603/s1, Figure S1: Determination of the stoichiometry, Figure S2: Spectra of fluoroquinolones, Figure S3: Spectra of $\beta$-lactams, Figure S4: Pictures of CIP and CIP-Fe, Figure S5: Chemical structure of fluoroquinolones, Figure S6: Chemical structure of $\beta$-lactams, Figure S7: Spectra for the mixture of CIP and ferric ions, Figure S8: Spectra for the mixture of DCX and ferric ions, Figure S9: Chromatograms, Figure S10: Mechanistic pathways for CIP, Figure S11: Products accumulation, Figure S12: Antimicrobial activity. Table S1: Ratio between rate constants, Table S2: Main fragments MS analysis, Table S3: Energy of photons.

Author Contributions: Conceptualization, E.A.S.-G., J.P., Y.Á.-T. and R.A.T.-P.; methodology, E.A.S.-G. and Y.L.M.-M.; formal analysis, E.A.S.-G., Y.L.M.-M. and J.S.-A.; investigation, E.A.S.-G. and Y.L.M.-M.; resources, J.P. and R.A.T.-P.; writing-original draft preparation, E.A.S.-G. and Y.L.M.-M.; writingreview and editing, J.P., J.S.-A., Y.Á.-T. and R.A.T.-P.; supervision, E.A.S.-G., J.P. and R.A.T.-P.; project administration, E.A.S.-G., J.P.; funding acquisition, J.P. and R.A.T.-P. All authors have read and agreed to the published version of the manuscript.

Funding: This research was funded by MINCIENCIAS COLOMBIA, grant "project No. 111577757323", and UNIREMINGTON grant "4000000287 (Contract No. 80740-680-2020)". The APC was funded by UNIREMINGTON.

Institutional Review Board Statement: Not applicable.

Informed Consent Statement: Not applicable.

Data Availability Statement: Data are available through direct requesting to the corresponding authors by email.

Acknowledgments: Efraím Serna-Galvis thanks MINCIENCIAS COLOMBIA for his postdoctoral fellowship (Convocatoria 848 de 2019).

Conflicts of Interest: The authors declare no conflict of interest.

\section{References}

1. Chaturvedi, P.; Shukla, P.; Giri, B.S.; Chowdhary, P.; Chandra, R.; Gupta, P.; Pandey, A. Prevalence and hazardous impact of pharmaceutical and personal care products and antibiotics in environment: A review on emerging contaminants. Environ. Res. 2021, 194, 110664. [CrossRef] [PubMed]

2. Rizzo, L.; Malato, S.; Antakyali, D.; Beretsou, V.G.; Đolić, M.B.; Gernjak, W.; Heath, E.; Ivancev-Tumbas, I.; Karaolia, P.; Ribeiro, A.R.; et al. Consolidated vs new advanced treatment methods for the removal of contaminants of emerging concern from urban wastewater. Sci. Total Environ. 2019, 655, 986-1008. [CrossRef] [PubMed] 
3. Rodriguez-Mozaz, S.; Vaz-Moreira, I.; Della Giustina, S.V.; Llorca, M.; Barceló, D.; Schubert, S.; Berendonk, T.U.; Michael-Kordatou, I.; Fatta-Kassinos, D.; Martinez, J.L.; et al. Antibiotic residues in final effluents of European wastewater treatment plants and their impact on the aquatic environment. Environ. Int. 2020, 140, 105733. [CrossRef] [PubMed]

4. Manaia, C.M.; Rocha, J.; Scaccia, N.; Marano, R.; Radu, E.; Biancullo, F.; Cerqueira, F.; Fortunato, G.; Iakovides, I.C.; Zammit, I.; et al. Antibiotic resistance in wastewater treatment plants: Tackling the black box. Environ. Int. 2018, 115, 312-324. [CrossRef]

5. Singer, A.C.; Shaw, H.; Rhodes, V.; Hart, A. Review of Antimicrobial Resistance in the Environment and Its Relevance to Environmental Regulators. Front. Microbiol. 2016, 7, 1728. [CrossRef]

6. Triggiano, F.; Calia, C.; Diella, G.; Montagna, M.T.; De Giglio, O.; Caggiano, G. The Role of Urban Wastewater in the Environmental Transmission of Antimicrobial Resistance: The Current Situation in Italy (2010-2019). Microorganisms 2020, 8, 1567. [CrossRef] [PubMed]

7. WHO. Antibiotic Resistance. Available online: https://www.who.int/news-room/fact-sheets/detail/antibiotic-resistance (accessed on 7 August 2021).

8. Chen, J.; Wang, Y.; Qian, Y.; Huang, T. Fe(III)-promoted transformation of $\beta$-lactam antibiotics: Hydrolysis vs oxidation. J. Hazard. Mater. 2017, 335, 117-124. [CrossRef] [PubMed]

9. Adachi, F.; Yamamoto, A.; Takakura, K.-I.; Kawahara, R. Occurrence of fluoroquinolones and fluoroquinolone-resistance genes in the aquatic environment. Sci. Total Environ. 2013, 444, 508-514. [CrossRef] [PubMed]

10. Korte, D.; Tomsič, G.; Bratkič, A.; Franko, M.; Budasheva, H. Determination of Iron in Environmental Water Samples by FIA-TLS. Acta Chim. Slov. 2019, 66, 814-820. [CrossRef]

11. Lee, S.; Uliana, A.; Taylor, M.K.; Chakarawet, K.; Bandaru, S.R.S.; Gul, S.; Xu, J.; Ackerman, C.M.; Chatterjee, R.; Furukawa, H.; et al. Iron detection and remediation with a functionalized porous polymer applied to environmental water samples. Chem. Sci. 2019, 10, 6651-6660. [CrossRef] [PubMed]

12. Alekseev, V.G. Metal complexes of penicillins and cephalosporins (Review). Pharm. Chem. J. 2012, 45, 679-697. [CrossRef]

13. Uivarosi, V. Metal Complexes of Quinolone Antibiotics and Their Applications: An Update. Mollecules 2013, $18,11153-11197$. [CrossRef] [PubMed]

14. Elmolla, E.; Chaudhuri, M. Optimization of Fenton process for treatment of amoxicillin, ampicillin and cloxacillin antibiotics in aqueous solution. J. Hazard. Mater. 2009, 170, 666-672. [CrossRef] [PubMed]

15. Marjanovic, M.; Giannakis, S.; Grandjean, D.; de Alencastro, L.F.; Pulgarin, C. Effect of $\mu \mathrm{M}$ Fe addition, mild heat and solar UV on sulfate radical-mediated inactivation of bacteria, viruses, and micropollutant degradation in water. Water Res. 2018, 140, $220-231$. [CrossRef] [PubMed]

16. Garcia-Segura, S.; Garrido, J.A.; Rodríguez, R.M.; Cabot, P.L.; Centellas, F.; Arias, C.; Brillas, E. Mineralization of flumequine in acidic medium by electro-Fenton and photoelectro-Fenton processes. Water Res. 2012, 46, 2067-2076. [CrossRef] [PubMed]

17. Sciscenko, I.; Arques, A.; Varga, Z.; Bouchonnet, S.; Monfort, O.; Brigante, M.; Mailhot, G. Significant role of iron on the fate and photodegradation of enrofloxacin. Chemosphere 2021, 270, 129791. [CrossRef]

18. Serna-Galvis, E.A.; Cáceres-Peña, A.C.; Torres-Palma, R.A. Elim-Ination of representative fluoroquinolones, penicillins, and cephalosporins by solar photo-Fenton: Degradation routes, primary transformations, degradation improvement by citric acid addition, and antimicrobial activity evolution. Environ. Sci. Pollut. Res. 2020, 27, 41381-41393. [CrossRef] [PubMed]

19. Vidal, J.; Huiliñir, C.; Santander, R.; Silva-Agredo, J.; Torres-Palma, R.A.; Salazar, R. Degradation of ampicillin antibiotic by electrochemical processes: Evaluation of antimicrobial activity of treated water. Environ. Sci. Pollut. Res. 2019, 26, 4404-4414. [CrossRef]

20. Montoya-Rodríguez, D.M.; Serna-Galvis, E.A.; Ferraro, F.; Torres-Palma, R.A. Degradation of the emerging concern pollutant ampicillin in aqueous media by sonochemical advanced oxidation processes-Parameters effect, removal of antimicrobial activity and pollutant treatment in hydrolyzed urine. J. Environ. Manag. 2020, 261, 110224. [CrossRef]

21. Giraldo-Aguirre, A.L.; Serna-Galvis, E.A.; Erazo-Erazo, E.D.; Silva-Agredo, J.; Giraldo-Ospina, H.; Flórez-Acosta, O.A.; Torres-Palma, R.A. Removal of $\beta$-lactam antibiotics from pharmaceutical wastewaters using photo-Fenton process at nearneutral pH. Environ. Sci. Pollut. Res. 2017, 25, 20293-20303. [CrossRef]

22. Elmolla, E.S.; Chaudhuri, M. Degradation of the antibiotics amoxicillin, ampicillin and cloxacillin in aqueous solution by the photo-Fenton process. J. Hazard. Mater. 2009, 172, 1476-1481. [CrossRef] [PubMed]

23. Antonin, V.S.; Santos, M.C.; Garcia-Segura, S.; Brillas, E. Electrochemical incineration of the antibiotic ciprofloxacin in sulfate medium and synthetic urine matrix. Water Res. 2015, 83, 31-41. [CrossRef] [PubMed]

24. El Najjar, N.H.; Deborde, M.; Journel, R.; Leitner, N.K.V. Aqueous chlorination of levofloxacin: Kinetic study and transformation product identification. Water Res. 2013, 47, 121-129. [CrossRef] [PubMed]

25. He, K.; Soares, A.D.; Adejumo, H.; McDiarmid, M.; Squibb, K.; Blaney, L. Detection of a wide variety of human and veterinary fluoroquinolone antibiotics in municipal wastewater and wastewater-impacted surface water. J. Pharm. Biomed. Anal. 2015, 106, 136-143. [CrossRef] [PubMed]

26. Wolfson, J.S.; Hooper, D.C. The fluoroquinolones: Structures, mechanisms of action and resistance, and spectra of activity in vitro. Antimicrob. Agents Chemother. 1985, 28, 581-586. [CrossRef]

27. Dodd, M.C.; Shah, A.D.; Von Gunten, U.; Huang, C.-H. Interactions of Fluoroquinolone Antibacterial Agents with Aqueous Chlorine: Reaction Kinetics, Mechanisms, and Transformation Pathways. Environ. Sci. Technol. 2005, 39, 7065-7076. [CrossRef]

28. Kümmerer, K. Antibiotics in the aquatic environment-A review-Part I. Chemosphere 2009, 75, 417-434. [CrossRef] [PubMed] 
29. Cha, J.M.; Yang, S.; Carlson, K.H. Trace determination of $\beta$-lactam antibiotics in surface water and urban wastewater using liquid chromatography combined with electrospray tandem mass spectrometry. J. Chromatogr. A 2006, 1115, 46-57. [CrossRef]

30. Patel, M.; Kumar, R.; Kishor, K.; Mlsna, T.; Pittman, C.U., Jr.; Mohan, D. Pharmaceuticals of Emerging Concern in Aquatic Systems: Chemistry, Occurrence, Effects, and Removal Methods. Chem. Rev. 2019, 119, 3510-3673. [CrossRef]

31. Martín-Sómer, M.; Moreno-SanSegundo, J.; Álvarez-Fernández, C.; van Grieken, R.; Marugán, J. High-performance low-cost solar collectors for water treatment fabricated with recycled materials, open-source hardware and 3d-printing technologies. Sci. Total Environ. 2021, 784, 147119. [CrossRef] [PubMed]

32. Serna-Galvis, E.A.; Silva-Agredo, J.; Giraldo-Aguirre, A.L.; Flórez-Acosta, O.A.; Torres-Palma, R.A. High frequency ultrasound as a selective advanced oxidation process to remove penicillinic antibiotics and eliminate its antimicrobial activity from water. Ultrason. Sonochem. 2016, 31, 276-283. [CrossRef]

33. Eldin, F.; Suliman, O.; Sultan, S.M. Sequential injection technique employed for stoichiometric studies, optimization and quantitative determination of some fluoroquinolone antibiotics complexed with iron(III) in sulfuric acid media. Talanta 1996, 43, 559-568. [CrossRef]

34. Eze, F.I.; Ajali, U.; Ukoha, P.O. Synthesis, Physicochemical Properties, and Antimicrobial Studies of Iron (III) Complexes of Ciprofloxacin, Cloxacillin, and Amoxicillin. Int. J. Med. Chem. 2014, 2014, 1-6. [CrossRef] [PubMed]

35. Szabó, L.; Tóth, T.; Engelhardt, T.; Rácz, G.; Mohácsi-Farkas, C.; Takács, E.; Wojnárovits, L. Change in hydrophilicity of penicillins during advanced oxidation by radiolytically generated $\mathrm{OH}$ compromises the elimination of selective pressure on bacterial strains. Sci. Total Environ. 2016, 551, 393-403. [CrossRef] [PubMed]

36. Serna-Galvis, E.A.; Ferraro, F.; Silva-Agredo, J.; Torres-Palma, R.A. Degradation of highly consumed fluoroquinolones, penicillins and cephalosporins in distilled water and simulated hospital wastewater by UV254 and UV254/persulfate processes. Water Res. 2017, 122, 128-138. [CrossRef]

37. Zhad, H.R.L.Z.; Lai, R.Y. Iron(III)-mediated Electrochemical Detection of Levofloxacin in Complex Biological Samples. Electroanalysis 2017, 29, 2672-2677. [CrossRef]

38. Efthimiadou, E.K.; Karaliota, A.; Psomas, G. Mononuclear metal complexes of the second-generation quinolone antibacterial agent enrofloxacin: Synthesis, structure, antibacterial activity and interaction with DNA. Polyhedron 2008, 27, 1729-1738. [CrossRef]

39. Albini, A.; Monti, S. Photophysics and photochemistry of fluoroquinolones. Chem. Soc. Rev. 2003, 32, 238-250. [CrossRef] [PubMed]

40. Aristilde, L.; Sposito, G. Molecular Modeling of Metal Complexation by a Fluoroquinolone Antibiotic. Environ. Toxicol. Chem. 2008, 27, 2304-2310. [CrossRef] [PubMed]

41. Al-Khodir, F.A.I.; Refat, M.S. Spectroscopic Elaboration and Structural Characterizations of New Fe(III), Pd(II), and Au(III) Ampicillin Complexes: Metal-Antibiotic Ligational Behaviors. J. Pharm. Innov. 2015, 10, 335-347. [CrossRef]

42. Chen, J.; Sun, P.; Zhou, X.; Zhang, Y.; Huang, C.-H. Cu(II)-Catalyzed Transformation of Benzylpenicillin Revisited: The Overlooked Oxidation. Environ. Sci. Technol. 2015, 49, 4218-4225. [CrossRef]

43. Anacona, J.; Noriega, N.; Camus, J. Synthesis, characterization and antibacterial activity of a tridentate Schiff base derived from cephalothin and sulfadiazine, and its transition metal complexes. Spectrochim. Acta Part A Mol. Biomol. Spectrosc. 2015, 137, 16-22. [CrossRef] [PubMed]

44. Wei, X.; Chen, J.; Xie, Q.; Zhang, S.; Li, Y.; Zhang, Y.; Xie, H. Photochemical behavior of antibiotics impacted by complexation effects of concomitant metals: A case for ciprofloxacin and Cu(ii). Environ. Sci. Process. Impacts 2015, 17, 1220-1227. [CrossRef] [PubMed]

45. Wang, S.; Wang, Z.; Hao, C.; Peijnenburg, W.J.G.M. DFT/TDDFT insights into effects of dissociation and metal complexation on photochemical behavior of enrofloxacin in water. Environ. Sci. Pollut. Res. 2018, 25, 30609-30616. [CrossRef] [PubMed]

46. Wang, S.; Wang, Z. Elucidating Direct Photolysis Mechanisms of Different Dissociation Species of Norfloxacin in Water and Mg2+ Effects by Quantum Chemical Calculations. Molecules 2017, 22, 1949. [CrossRef] [PubMed]

47. Wang, X.-H.; Lin, A. Phototransformation of Cephalosporin Antibiotics in an Aqueous Environment Results in Higher Toxicity. Environ. Sci. Technol. 2012, 46, 12417-12426. [CrossRef] [PubMed]

48. Pérez, J.S.; Arzate, S.; Soriano-Molina, P.; Sánchez, J.G.; López, J.C.; Plaza-Bolaños, P. Neutral or acidic pH for the removal of contaminants of emerging concern in wastewater by solar photo-Fenton? A techno-economic assessment of continuous raceway pond reactors. Sci. Total Environ. 2020, 736, 139681. [CrossRef]

49. Porras, J.; Bedoya, C.; Silva-Agredo, J.; Santamaría, A.; Fernández, J.J.; Torres-Palma, R.A. Role of humic substances in the degradation pathways and residual antibacterial activity during the photodecomposition of the antibiotic ciprofloxacin in water. Water Res. 2016, 94, 1-9. [CrossRef]

50. Sturini, M.; Speltini, A.; Maraschi, F.; Pretali, L.; Profumo, A.; Fasani, E.; Albini, A.; Migliavacca, R.; Nucleo, E. Photodegradation of fluoroquinolones in surface water and antimicrobial activity of the photoproducts. Water Res. 2012, 46, 5575-5582. [CrossRef]

51. Fasani, E.; Profumo, A.; Albini, A. Structure and Medium-Dependent Photodecomposition of Fluoroquinolone Antibiotics. Photochem. Photobiol. 1998, 68, 666-674. [CrossRef]

52. Fasani, E.; Negra, F.F.B.; Mella, M.; Monti, S.; Albini, A. Photoinduced C-F Bond Cleavage in Some Fluorinated 7-Amino-4quinolone-3-carboxylic Acids. J. Org. Chem. 1999, 64, 5388-5395. [CrossRef]

53. Salma, A.; Thoröe-Boveleth, S.; Schmidt, T.C.; Tuerk, J. Dependence of transformation product formation on $\mathrm{pH}$ during photolytic and photocatalytic degradation of ciprofloxacin. J. Hazard. Mater. 2016, 313, 49-59. [CrossRef] 
54. Martinez, L.; Bilski, P.; Chignell, C.F. Effect of Magnesium and Calcium Complexation on the Photochemical Properties of Norfloxacin. Photochem. Photobiol. 1996, 64, 911-917. [CrossRef]

55. Ma, H.H.M.; Chiu, F.C.K.; Li, R.C. Mechanistic Investigation of the Reduction in Antimicrobial Activity of Ciprofloxacin by Metal Cations. Pharm. Res. 1997, 14, 366-370. [CrossRef]

56. Seedher, N.; Agarwal, P. Effect of metal ions on some pharmacologically relevant interactions involving fluoroquinolone antibiotics. Drug Metab. Drug Interact. 2010, 25, 17-24. [CrossRef] [PubMed]

57. Anacona, J.R.; Estacio, J. Synthesis and Antibacterial Activity of Cefixime Metal Complexes. Transit. Met. Chem. 2006, 31, 227-231. [CrossRef]

58. Anacona, J.R.; Acosta, F. Synthesis and antibacterial activity of cephradine metal complexes. J. Co-Ord. Chem. 2006, 59, 621-627. [CrossRef]

59. Anacona, J.R.; Silva, G.D. Synthesis and antibacterial activity of cefotaxime metal complexes. J. Chil. Chem. Soc. 2005, 50, 447-450. [CrossRef]

60. Hooper, D.C.; Jacoby, G.A. Topoisomerase Inhibitors: Fluoroquinolone Mechanisms of Action and Resistance. Cold Spring Harb. Perspect. Med. 2016, 6, a025320. [CrossRef] [PubMed]

61. Paul, T.; Dodd, M.C.; Strathmann, T.J. Photolytic and photocatalytic decomposition of aqueous ciprofloxacin: Transformation products and residual antibacterial activity. Water Res. 2010, 44, 3121-3132. [CrossRef] 